\title{
SIMULASI PENENTUAN LOKASI GANGGUAN SATU FASA PADA JARINGAN TEGANGAN MENENGAH 20 KV BERBASIS ARDUINO MEGA 2560 DILENGKAPI DENGAN MONITORING MELALUI VTSCADA
}

\author{
Danu Nur Ashifa, Arkhan Subari \\ Program Studi Diploma III Teknik Elektro, \\ Sekolah Vokasi Universitas Diponegoro \\ Jl. Prof. Soedarto, SH, Kampus Undip Tembalang, Semarang, Indonesia 50275
}

\begin{abstract}
Danu Nur Ashifa, Arkhan Subari in this paper explain that in a distribution network of $20 \mathrm{KV}$, short circuit interference often occurs. Short circuit interference will produce a fault current that is felt by protection equipment. Each fault current will differ depending on the distance of the interference. Determining the distance of interference can not be displayed in SCADA, SCADA will only display the amount of interference and which equipment works. Determination of distance is carried out after analysis by the officer. Based on this matter the compiler makes a simulation tool where the tool can monitor the location of the disturbance from the nearest protective equipment that feels a single phase short circuit interference. The simulation tool consists of Arduino Mega 2560 which functions as a control center. The input used is a potentiometer as a simulator of the impedance magnitude that occurs during a single phase short circuit where the potentiometer will provide input in the form of a signal. And Omron LY2N relay which functions as protection equipment. After the experiment, the results obtained are that the tool can determine the location of interference from the nearest protection equipment based on changes in the bits read by Arduino. The larger the bits read by Arduino, the more distant the interference occurs from the protection equipment. 125 bits will produce an Arduino impedance calculation of 2.6 ohms so that the fault location is $0 \mathrm{~km}$ from PMT while 1023 bits will produce an impedance calculation of $21.30 \mathrm{ohms} \mathrm{so} \mathrm{that}$ the fault location is $4.5 \mathrm{~km}$ from $\mathrm{SSO}$.
\end{abstract}

Keywords: Arduino Mega 2560; short circuit fault current; GFR; fault location;

\section{PENDAHULUAN}

Sistem distribusi merupakan bagian dari sistem ketenagalistrikan yang paling dekat dengan beban/pelanggan, yang menyalurkan tenaga listrik melalui tegangan $20 \mathrm{KV}$ pada Jaringan Tegangan Menengah (JTM) serta tegangan 220/380 V pada Jaringan Tegangan Rendah (JTR) ${ }^{[1]}$. Sebagian besar jaringan distribusi $20 \mathrm{KV}$ di Indonesia mempergunakan Saluran Udara Tegangan Menengah (SUTM) yang melintasi udara terbuka, sehingga tidak menutup kemungkinan terjadinya gangguan seperti gangguan yang diakibatkan pepohonan dan binatang. Hal ini dapat mengkibatkan terjadinya hubung singkat antar fasa atau antara fasa ke tanah, yang dapat bersifat temporer maupun permanen.

Untuk mengatasi hal tersebut maka diperlukan pemasangan peralatan proteksi yang berupa relai arus lebih (OCR) yang mengamankan gangguan 2 fasa maupun 3 fasa serta relai gangguan tanah (GFR) untuk mengamankan gangguan fasa $-\operatorname{tanah}^{[2]}$. GFR terdapat pada peralatan-peralatan proteksi jaringan distribusi $20 \mathrm{KV}$. GFR disetting berdasarkan arus gangguan yang terjadi pada jaringan tersebut. Besarnya arus gangguan pada setiap jarak berbedabeda dikarenakan impedansi yang ikut berubah sesuai panjangmjaringan. Peralatan-peralatan proteksi dapat mengamankan arus gangguan yang terjadi namun tidak dapat menampilkan perkiraan jarak gangguan tersebut terjadi. Jarak gangguan baru dapat diketahui setelah menganilisis data gangguan yang ada pada data event peralatan proteksi atau dari tampilan
SCADA. SCADA belum dapat menampilkan perkiraan jarak gangguan tersebut, SCADA berfungsi hanya untuk monitoring besarnya arus gangguan yang terbaca oleh peralatan proteksi dan daerah padam akibat gangguan serta controlling peralatan proteksi saat penormalan. Sehingga dalam melakukan penormalan petugas melakukan sweeping sepanjang jaringan untuk mengetahui penyebab gangguan tersebut.

Untuk itu diperlukan suatu alat yang dapat dengan mudah mendeteksi dan memonitor letak gangguan secara nirkabel sehingga penanganan untuk gangguan dapat lebih cepat dilakukan. Data acuan dalam penelitian ini adalah data pada GI Srondol, Penyulang SRL 01.

\section{KONSEP DASAR PEMBUATAN ALAT}

Gangguan hubung singkat satu fasa pada jaringan distribusi terjadi karena adanya hubung singkat antara fasa dan netral pada jaringan, arus gangguan yang dihasilkan cukup besar yang dikhawatirkan dapat merusak peralatan pada jaringan. Sehingga perlu dilakukan pengamanan oleh peralatan proteksi. Pemasangan peralatan proteksi pun mengacu pada besarnya arus gangguan yang terjadi pada jaringan yang dilindunginya agar peralatan tersebut dapat melindungi jaringan dengan baik dan menekan daerah padam seminimum mungkin. Namun saat terjadi gangguan petugas sering kali kesulitan dalam memprediksi lokasi gangguan karena dalam HMI tidak ditampilkan 
perkiraan lokasi gangguan sehingga petugas harus melakukan sweeping di jaringan yang padam tersebut.

Penentuan lokasi gangguan pada jaringan distribusi didasarkan pada perhitungan arus gangguan yang terjadi dan dibaca oleh peralatan proteksi. Perhitungan dilakukan oleh petugas proteksi dengan cara menganalisi besar arus gangguan. Besarnya arus gangguan berubah berdasarkan jarak gangguan tersebut dari pangkal jaringan yaitu PMT outgoing, sehingga semakin jauh gangguan tersebut dari PMT outgoing maka semakin kecil arus gangguan yang terjadi.

Penyulang SRL01 menggunakan jenis kabel penghantar AAC dengan luas penampang $150 \mathrm{~mm} 2$ dan kabel AAAC dengan luas penampang $240 \mathrm{~mm} 2$ serta data penyulang SRL01 pada Gambar 1.

Penyulang SRL 01 memiliki panjang penyulang $8 \mathrm{~km}$ dengan jarak recloser dengan PMT outgoing $2 \mathrm{~km}$ dan jarak SSO dari recloser $1.5 \mathrm{~km}$. Gambaran jarak dan letak peralatan proteksi pada penyulang SRL 01 ditunjukkan pada Gambar 2.

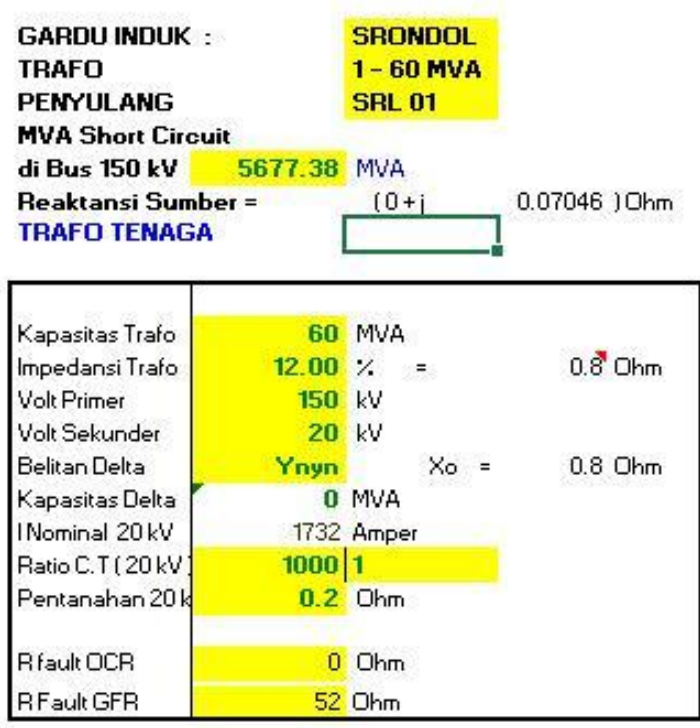

Gambar 1. Data Trafo I GI Srondol.

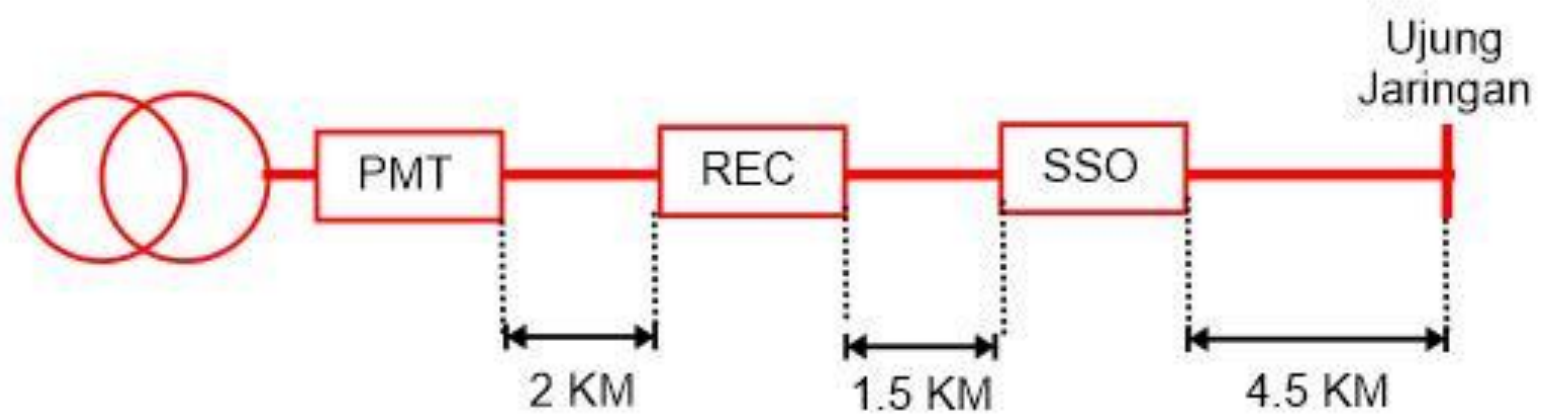

Gambar 2. Jarak antar peralatan proteksi di penyulang SRL 01.

Penelitian ini akan mensimulasikan penentuan lokasi gangguan arus hubung singkat satu fasa pada jaringan tegangan menengah $20 \mathrm{KV}$. Alat akan menentukan prediksi lokasi gangguan berdasarkan arus gangguan yang dimasukan pada alat. Arus diatur dengan perhitungan tegangan dibagi dengan impedansi. Impedansi didapat dari sinyal digital yang dikonversi dari sinyal analog menjadi digital pada Arduino dengan potensiometer sebagai masukan.

Perhitungan jarak gangguan berdasarkan arus hubung singkat dihitung dengan menggunakan persamaan (1) dan (2). ${ }^{[2]}$

$$
\begin{aligned}
& i_{\text {hs }} \text { 1phasa }=\frac{3 \text { Ephasa-netral }}{\mathrm{Z} 1+\mathrm{Z} 2+\mathrm{Z} 0+\mathrm{Zfault}} \\
& x=\frac{\frac{3 \times 20000 / \sqrt{3}}{i_{h s} 1 \text { phasa }}-2.50549}{2.400625}
\end{aligned}
$$

Keterangan : ihs 1phasa

: Arus hubung singkat (A) $\mathrm{X}$

: Jarak gangguan (m)
Hasil perhitungan jarak gangguan ditunjukkan pada tabel 1 .

Tabel 1. Hasil perhitungan jarak gangguan

\begin{tabular}{cccc}
\hline No & Ihs 1 phasa (A) & Jarak (km) & Z total (ohm) \\
\hline 1 & 13268.358 & 0 & 2.61 \\
2 & 7733.800 & 0.8 & 4.48 \\
3 & 5456.904 & 1.6 & 6.35 \\
4 & 4215.659 & 2.4 & 8.22 \\
5 & 3434.421 & 3.2 & 10.09 \\
6 & 2897.458 & 4 & 11.96 \\
7 & 2505.693 & 4.8 & 13.82 \\
8 & 2207.249 & 5.6 & 15.69 \\
9 & 1972.331 & 6.4 & 17.56 \\
10 & 1626.179 & 8 & 20.30 \\
\hline
\end{tabular}

Impedansi pada jarak terdekat dari PMT adalah 2,61 $\Omega$ sedangkan pada ujung jaringan pada jarak $8 \mathrm{~km}$ memiliki impedansi sebesar 21,30 $\Omega$. Angka-angka ini digunakan untuk melakukan proses 
kalibrasi atau penskalaan bit ADC pada arduini dengan nilai impedansi yang diwakilkan dengan nilai potensiometer. Arduino Mega 2560 memiliki spesifikasi sebesar 10 bit sehingga memiliki skala sebesar 0-1023. ${ }^{[3]}$ Didapat impedansi pada ujung jaringan sebesar 21,30 $\Omega$ sedangkan nilai bit maksimal adalah 1023 sehingga untuk melakukan perbandingan nilai bit terukur akan dikali dengan hasil bagi antara bit maksimal dengan impedansi pada ujung jaringan. Skala nilai untuk setiap bit ADC dapart dicari dengan menggunakan persamaan (3).

skala $=\frac{1023}{21.30}=0.020821114$

Hasil perbandingan bit dengan jarak gangguan dan impedansi berdasarkan perhitungan menggunakan persamaan (3) ditunjukkan pada Tabel 2.

Tabel 2. Perbandingan bit dengan jarak gangguan

\begin{tabular}{cccc}
\hline No & Bit & Impedansi & Jarak $(\mathrm{km})$ \\
\hline 1 & 125 & 2.60 & 0.04 \\
2 & 200 & 4.16 & 0.69 \\
3 & 300 & 6.25 & 1.56 \\
4 & 400 & 8.33 & 2.43 \\
5 & 500 & 10.41 & 3.29 \\
6 & 600 & 12.49 & 4.16 \\
7 & 700 & 14.58 & 5.03 \\
8 & 800 & 16.66 & 5.90 \\
9 & 900 & 18.74 & 6.76 \\
10 & 1023 & 21.30 & 8.00 \\
\hline
\end{tabular}

Setelah diketahui skala diantara bit dengan impedansi maka selanjutnya dilakukan pemetaan pada jaringan agar dapat ditentukan proteksi mana yang terdekat dari gangguan.

Gambar 3. menunjukan pemetaan dari impedansi dan pembacaan bit pada jaringan.
Pembacaan impedansi dibaca dengan program AnalogRead pada Arduino sehingga apabila potensiometer yang dihubungkan pada pin Analog diputar dapat mengubah nilai bit yang dibaca oleh Arduino.

adc $=$ AnalogRead (A14);

Impedansi $=$ adc $* 0.020821114$;

Karena pada alat simulasi yang akan ditampilkan sebagai input pada alat adalah arus gangguan maka nilai impedansi yang telah terukur dimasukan kedalam perhitungan arus hubung singkat 1 phasa terlebih dahulu. Dengan data pada gambar 1 . tegangan sekunder trafo pada penyulang SRL01 adalah $20 \mathrm{KV}$ sehingga arus dapat dihitung dengan persamaan (4).

arus $=\frac{34641.01615}{\text { impedansi }}$

Setelah arus dimasukan maka Arduino akan menghitung jarak gangguan tersebut dengan persamaan (2) sehingga didapat jarak gangguan dari PMT outgoing atau pangkal jaringan, setelah itu jarak akan dihitung kembali dan memzonasinya pada zona peralatan proteksi. Jarak recloser dari PMT outgoing adalah $2000 \mathrm{~m}$ sehingga untuk menentukan jarak gangguan dari recloser maka jarak dikurangi dengan jarak recloser sehingga : Jarak recloser $=$ jarak -2000

Sedangkan jarak SSO dari PMT adalah 3500 m sehingga untuk menentukan jarak dari SSO adalah dengan cara mengurankan jarak yang tebaca dari PMT outgoing dengan jarak SSO ke PMT, sehingga Jarak SSO = jarak -3500 . Dengan demikian didapat prediksi lokasi gangguan berdasarkan jarak peralatan proteksi terdekat tidak dari pangkal jaringan lagi. Dengan alat ini diharapkan dapat mempermudah dalam pencarian gangguan pada jaringan. Rancangan perangkaian alat dapat dilihat pada gambar 4 .

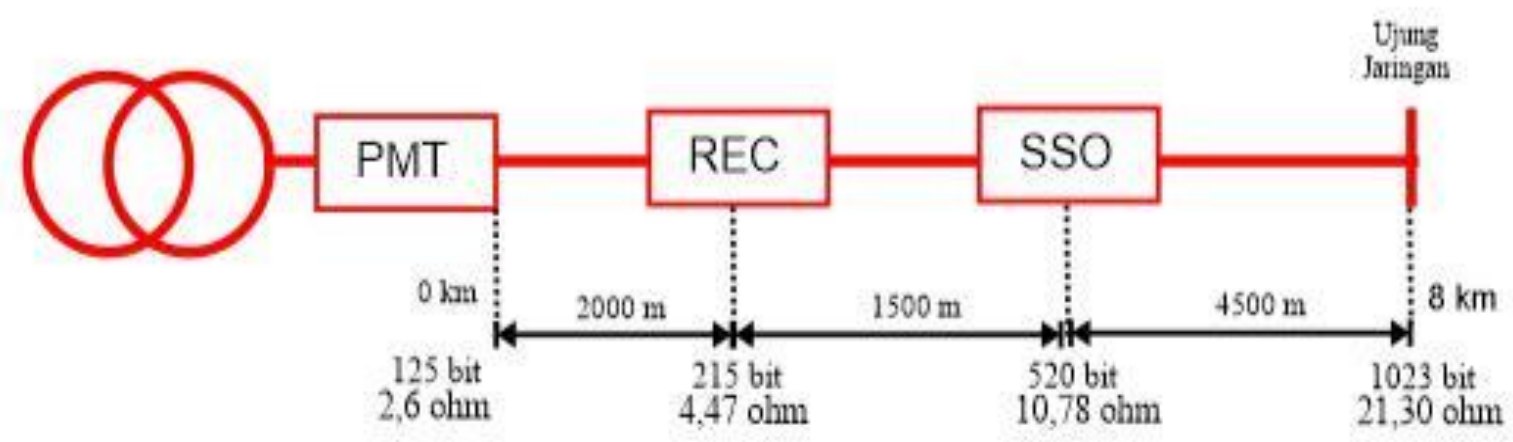

Gambar 3. Pemetaan jarak gangguan berdsarkan bit dan impedansi. 


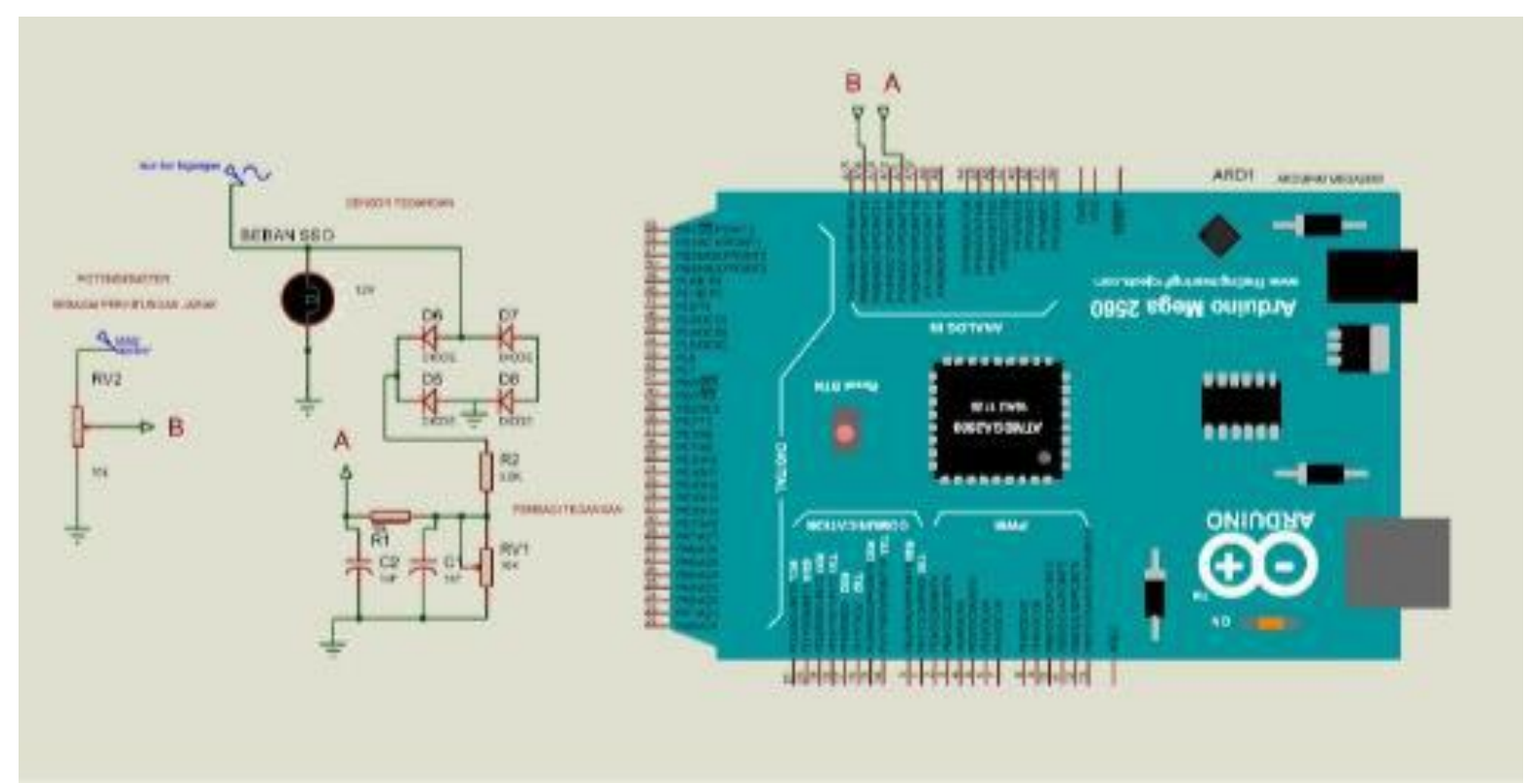

Gambar 4. Gambar rangkaian alat.

Diagram alur proses penentuan jarak gangguan dan proses monitoring menggunakan VTSCADA di tunjukkan pada Gambar 5 dan 6.

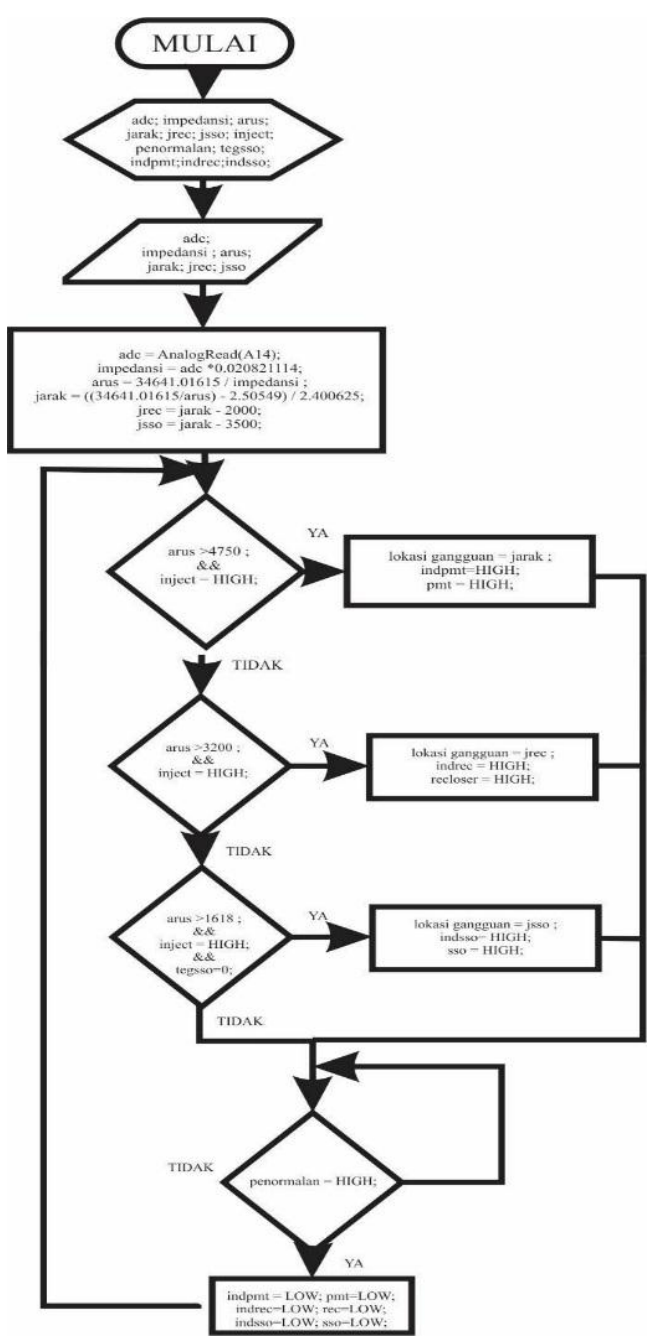

Gambar 5. Diagram alur penentuan jarak gangguan.

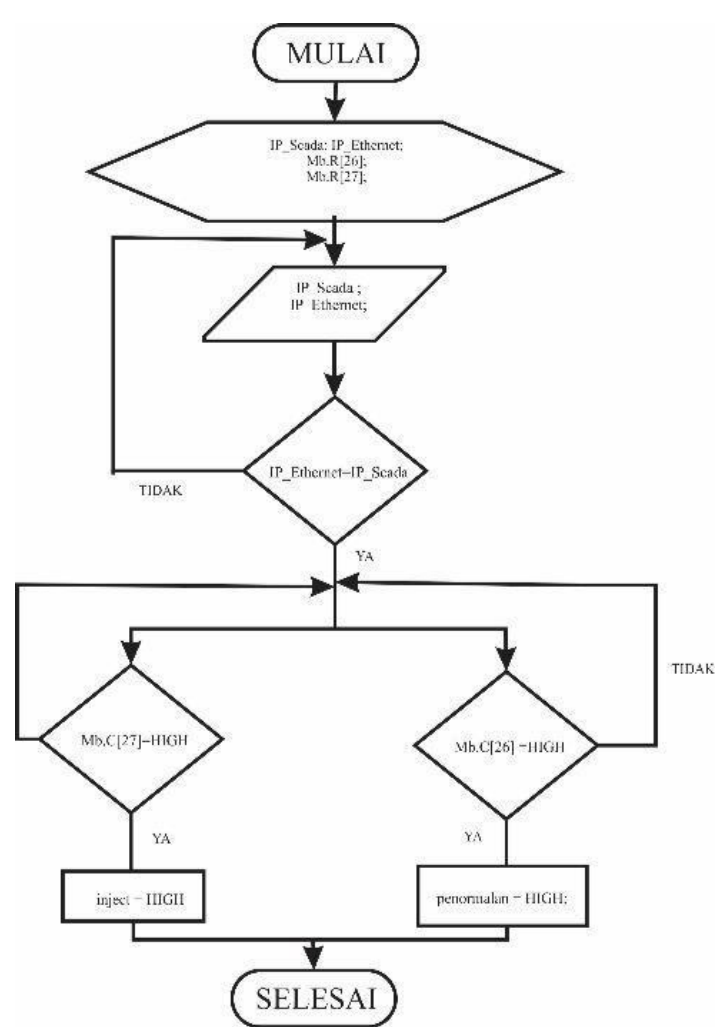

Gambar 6. Diagram alur monitoring sistem menggunakan VTSCADA

Injeksi arus dilakukan dengan melakukan perubahan pada variabel resistor. Variabel resistor berfungsi sebagai input ke Arduino Mega 2560. Input ini akan memproyeksikan tahanan yang ada pada jaringan $20 \mathrm{kv}$. Variabel resistor akan dirangkai dengan Arduino melalui pin Analog yang ada board Arduino Mega 2560. Dengan memanfaatkan fitur ADC (Analog to Digital Converter) yang ada pada Arduino maka Arduino dapat membaca input analog 
dari variabel resitor. ${ }^{[4]}$ Gambar rangkaian dari inputan ini ditunjukkan pada Gambar 7.

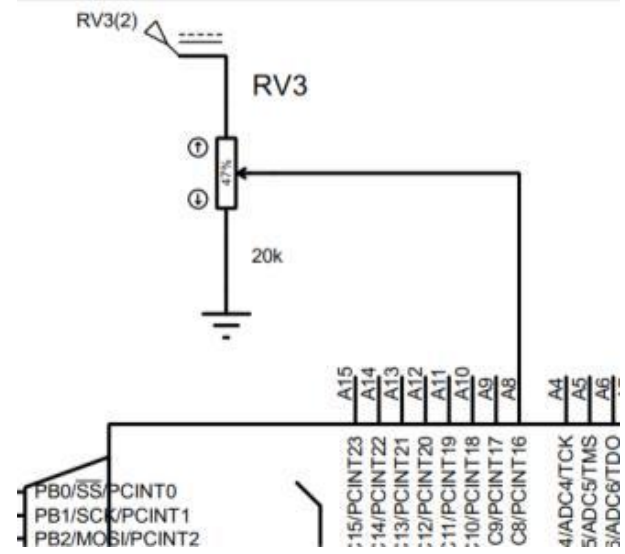

Gambar 7. Rangkaian Injeksi Arus

Software VTSCADA mampu untuk melakukan sistem kendali berbasis komputer yang dipakai untuk pengontrolan suatu proses tenaga listrik. Dapat juga manampilkan hasil besaran yang di ukur oleh sensor. Selain itu software juga dilengkapi oleh button ataupun switch yang mampu untuk menggerakan kontak relay pada rangkaian elektronika. ${ }^{[5]}$

Simulasi arus gangguan dilakukan dengan cara memutar potensiometer hingga mencapai arus gangguan yang diingkan. Putaran potensiometer akan memberi input berupa sinyal analog dan dikonversikan menjadi sinyal digital oleh Arduino yang memproyeksikan total hambatan yang ada lokasi gangguan pada jaringan tersebut.

Dari nilai hambatan itu dapat dihitung arus gangguan hubung singkat satu fasa menggunakan rumus yang telah dijabarkan sebelumnya. Gangguan yang di input kan adalah berupa gangguan permanen Untuk jarak gangguan akan ditampilkan dari relay proteksi terdekat dengan menekan tombol inject dimana juga akan terlihat kerja dari perlatan proteksi yang terpasang. Untuk mengembalikan relay ke dalam keadaan normal yaitu keadaan dimana arus gangguan belum diinject maka tekan tombol penormalan maka alat simulasi akan kembali ke keadaan normal dan siap melakukan percobaan berikutnya.

Setelah mendapat arus yang diinginkan lalu tekan push button untuk menginput arus tersebut agar dapat dilihat di mana letak gangguan tersebut dan bagaimana peralatan proteksi menanggapi gangguan tersebut. Peralatan proteksi telah disetting agar terjadi koordinasi yang baik.

HMI menggunakan personal computer dengan menghubungkannya menggunakan router ke Ethernet shield di Arduino Mega 2560. HMI digunakan untuk monitoring dan controlling alat. Monitoring dilakukan pada besaran arus prediksi lokasi gangguan dan keadaan relay. Untuk controlling HMI mengontrol penormalan dan inject arus ke alat.

\section{PENGUKURAN DAN PENGUJIAN}

Pengujian alat dilakukan untuk mengetahui apakah alat telah bekerja dengan baik yaitu menampilkan data sesuai dengan perhitungan menggunakan rumus yang ada. Pengujian dilkukan dengan melakukan inject arus pada sistem dengan cara melakukan perubahan nilai variabel resistor, seperti terlihat pada gambar 8 .

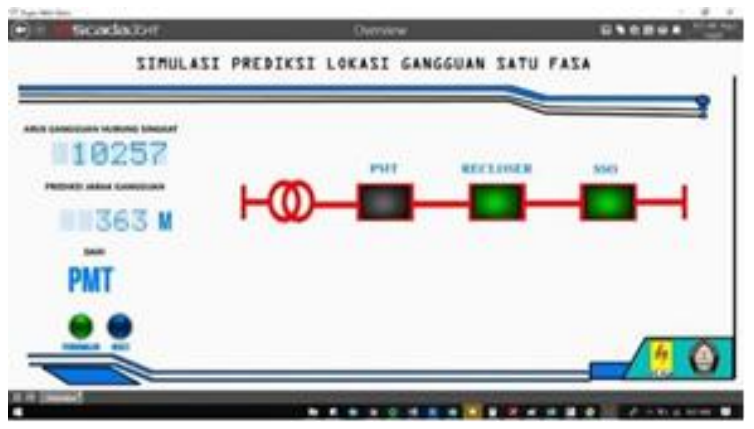

Gambar 8. Pengujian alat

Pada gambar 7, terlihat bahwa dengan memberikan arus ganguan sebesar $10257 \mathrm{~A}$, didapatkan bahwa jarak gangguan yang terjadi adalah 363 m dari PMT. Hasil perhitungan menggunakan persamaan (2) memberikan nilai yang sama, yaitu $363 \mathrm{~m}$. hasil pengujian dengan menggunakan ijeksi arus yang lain ditunjukkan pada tabel 3 dan 4 . Perbedaan yang terjadi antara pembacaan alat simulasi dengan VTSCADA adalah karena adanya delay.

Tabel 3. Hasil pembacaan input arus

\begin{tabular}{ccc}
\hline Percobaan & Arduino (A) & VTSCADA (A) \\
\hline 1 & 10244 & 10244 \\
2 & 9386 & 9386 \\
3 & 8060 & 8072 \\
4 & 7319 & 7318 \\
5 & 4316 & 4315 \\
6 & 4212 & 4212 \\
7 & 3887 & 3887 \\
8 & 3016 & 3016 \\
9 & 2015 & 2002 \\
10 & 1638 & 1638 \\
\hline
\end{tabular}

Tabel 4. Hasil pengujian lokasi gangguan

\begin{tabular}{cccc}
\hline Percobaan & Lokasi & $\begin{array}{c}\text { Arduino } \\
(\mathbf{m})\end{array}$ & $\begin{array}{c}\text { VTSCADA } \\
(\mathbf{m})\end{array}$ \\
\hline 1 & PMT & 265,78 & 365 \\
2 & PMT & 494,55 & 494 \\
3 & PMT & 744,59 & 744 \\
4 & PMT & 928,73 & 928 \\
5 & REC & 300,52 & 300 \\
6 & REC & 383,08 & 383 \\
7 & REC & 657,15 & 657 \\
8 & SSO & 241,63 & 241 \\
9 & SSO & 2618,44 & 2618 \\
10 & SSO & 4266,67 & 4266 \\
\hline
\end{tabular}




\section{KESIMPULAN}

Kesimpulan yang dapat diambil dari penelitian ini adalah :

- Jarak lokasi gangguan yang ditampilkan oleh alat simulasi sesuai dengan perhitungan lokasi gangguan. Saat arus gangguan yang dihitung oleh Arduino sebesar 10257 A maka alat akan membaca lokasi gangguan pada $363 \mathrm{M}$ dari PMT, dan ini sesuai dengan perhitungan mengguanakan rumus yang ada dalam pembahasan.

- Jarak lokasi gangguan ditentukan berdasarkan inject arus perhitungan gangguan yang diberikan, dimana arus gangguan akan berubah berdasarkan perubahan bit yang dibaca oleh Arduino. Saat bit yang dibaca oleh Arduino diantara 125 dan 215 bit akan menghasilkan perhitungan impedansi dari 2,6 sampai 4,47 $\Omega$ sehingga akan ditentukan lokasi sekitar 0-2 km dari PMT outgoing. Saat bit yang terbaca diantara 215 sampai 520 bit akan menghasilkan perhitungan impedansi sebesar 4,47 - 10,78 $\Omega$ sehingga akan ditentukan lokasi gangguan sekitar 0 - 1,5 km dari RECLOSER. Sedangkan apabila bit yang terbaca oleh Arduino adalah 520 - 1023 bit maka akan menghasilkan perhitungan impedansi $10,78-21,30 \Omega$ sehingga lokasi gangguan akan terbaca $0-4,5$ km dari SSO.

- Setiap indikator lampu yang terhubung dengan VTScada saat setiap tombol button ditekan dapat memberikan informasi valid sehingga dapat terdeteksi oleh mikrokontroler Arduino Mega 2560 sesuai dengan status dari relay dengan delay sebesar 0,9-1 detik pada saat PMT bekerja dan 11,9 - 12,1 pada saat RECLOSER dan SSO bekerja. Waktu delay ini terjadi karena VTScada membaca hasil pembacaan akhir dari kondisi relay dalam mengamankan gangguan hubung singkat satu fasa yang bersifat permanen.

\section{DAFTAR PUSTAKA}

1. PT.PLN (Persero) Pusat Pendidikan dan Pelatihan, 2010, Sistem Distribusi Tenaga Listrik, Jakarta : PT. PLN(Persero).

2. Sarimun, Wahyudi, 2012, Proteksi Sistem Distribusi Tenaga Listrik, Depok : Garamond.

3. Arduino \& Genuino Products, 2017, Getting Started with the Arduino Ethernet Shield, https://www.arduino.cc/en/Guide/ArduinoEther netShield.

4. Muda, Imam, 2013, Elektronika Dasar, Malang: Penerbit Gunung Samudera.

5. Kurniawan, Mohamad Rizki, 2017, Implementasi SCADA untuk monitoring koordinasi PMT dengan recloser sebagai proteksi pada jaringan 3 phasa berbasis arduino mega 2560, Semarang, Universitas Diponegoro. 